\title{
O USO DE TEMAS GERADORES NO PROCESSO DE ALFABETIZAÇÃO DE ADULTOS*
}

\author{
Jaqueline de Morais Costa, \\ da Faculdade Santa Amélia, Ponta Grossa-PR
}

\begin{abstract}
ResUmo: O presente artigo tem como objetivo relatar o processo de investigação realizado com alunos de um programa de alfabetização de adultos, ocorrido por meio de um estudo de caso. A pesquisa relatada teve como base o desenvolvimento de atividades com uso da metodologia proposta por Paulo Freire, utilizando-se o trabalho com temas geradores. Observou-se que o ensino por meio de temáticas ligadas ao cotidiano influencia diretamente no envolvimento dos alunos com as aulas e, por consequência, no êxito da aprendizagem. Verificou-se que essa proposta vem ao encontro das necessidades dos educandos, uma vez que proporciona a aquisição do conhecimento da leitura e da escrita, além de proporcionar um conhecimento relacionado com suas vidas.
\end{abstract}

Palavras-chave: Alfabetização de adultos. Temas geradores. Paulo Freire

INTRODUÇÃO

A Educação de Jovens e Adultos (EJA) é uma modalidade de ensino prevista na Lei de Diretrizes e Bases da Educação Brasileira n. 9394/96, a qual tem como objetivo atender a escolarização das pessoas que não tiveram acesso em idade de cursá-la (BRASIL, 1996).

Para tanto, a organização da escola que atende a essa modalidade precisa suprir as necessidades de seus frequentadores, sendo que a estrutura ofertada às crianças e adolescentes recebeu adaptações para atender aos jovens e adultos que buscam a educação.

\footnotetext{
* Artigo recebido em 18/7/2011 e aprovado em 9/4/2012.
} 
As etapas do ensino fundamental e médio, ofertadas para educação básica, também são oferecidas em modalidade EJA. Contudo, há ainda o imperativo de incluir muitos jovens e adultos nas primeiras lições de escrita e de leitura, momento esse nomeado de Alfabetização de Jovens e Adultos.

Desenvolver um trabalho inicial na alfabetização de jovens e adultos é bastante diferenciado do trabalho com crianças, visto aqueles possuírem, por meio de sua vivência, inúmeros conhecimentos que não podem ser desconsiderados pelo educador.

Diante dessas premissas, colocou-se como problemática do presente trabalho: "Como o educador pode atender às necessidades de alfabetização, considerando uma formação integral de alunos na modalidade de educação de jovens e adultos?"

Com o intuito de promover a alfabetização, de forma a respeitar a cultura dos educandos, esta pesquisa buscou investigar como a adoção de temas geradores poderia contribuir para o desenvolvimento dos educandos de um grupo pertencente ao Programa Paraná Alfabetizado.

Adotando-se temas do cotidiano dos envolvidos, viu-se a possibilidade de desenvolver os conhecimentos escolares de uma forma interdisciplinar, contextualizada e significativa aos educandos.

\section{FUNDAMENTAÇÃO TEÓRICA}

\section{A alfabetização de adultos}

A Educação de Jovens e Adultos no Brasil possui suas raízes na educação jesuítica ofertada aos indígenas brasileiros, os quais tiveram seu processo de alfabetização iniciado por atendimento da igreja católica por meio da catequese.

Já no que se refere às políticas públicas, Pilleti (1997) afirma que, na Constituição de 1934, havia a recomendação de atendimento educacional para o ensino primário às pessoas que não tiveram acesso à educação em idade própria. Porém, foi apenas ao final da década de 1940 (DI PIERRO, 2005) que se iniciaram vários movimentos de educação não formal - ligados a organizações sociais, à igreja católica e ao próprio governo - cujo objetivo seria promover educação a jovens e adultos analfabetos. Entre eles, a mais conhecida ação foi o Movimento Brasileiro de Alfabetização (MOBRAL), iniciado em torno de 1970 pelo regime militar que governava o Brasil na época. Esse movimento ofertava a educação chamada de integrada (equivalente hoje aos anos iniciais do ensino fundamental). Porém, segundo Oliveira e Paiva (2004), não reduziu mais do que $7 \%$ da população analfabeta brasileira. 
A atual Lei de Diretrizes e Bases da Educação (LDB, 9394/96) traz em sua redação, especificamente nos artigos 37 e 38, a obrigatoriedade e a gratuidade da oferta da educação para todos que não tiveram acesso na idade adequada, ou seja, o atendimento a jovens e adultos que não contemplaram sua escolaridade fundamental e média.

Segundo Oliveira e Paiva (2004), o Parecer do Conselho de Educação Básica (CEB) n. 11, de 2000, coloca que a EJA possui três funções: reparadora, por atender os cidadãos que outrora foram excluídos do sistema educacional; equalizadora, na tentativa de ofertar igualdade de oportunidades; e qualificadora, pois seu objetivo é oferecer formação também para o trabalho, como é o caso dos programas de qualificação profissional. Vale ressaltar que o referido parecer compreende a formação de maneira integral, definindo que a educação ocorre em qualquer momento e que seu objetivo é preparar melhor os cidadãos para as situações que os rodeiam.

Para que se propicie $o$ atendimento ao jovem e adulto em defasagem na sua escolarização, existem atualmente algumas modalidades de atendimento destinadas a jovens e adultos. Os programas de alfabetização de adultos geralmente são atendidos por programas governamentais, como o Brasil Alfabetizado, ou por Organizações Não Governamentais (ONGs), como é o caso do programa Alfabetização Solidária (ALFASOL). Sua finalidade é o de apenas alfabetizar, sendo que a Educação de Jovens e Adultos (EJA), de forma abrangente, visa o aprendizado na educação básica (fundamental e média) levando em consideração as características do público atendido (BRASIL, 1996).

Nessa perspectiva, a etapa de alfabetização possui suas características próprias e sua principal função é fornecer aos educandos ferramentas necessárias para facilitar suas vidas cotidianas. Portanto, essa fase precisa respeitar o contexto de seus participantes, sendo, então, que o emprego de temas geradores, como abordagem metodológica, torna-se uma estratégia interessante para atender a esses preceitos.

\section{Temas geradores}

O ensino por meio de temas geradores foi desenvolvido e aplicado por Paulo Freire, autor brasileiro de reconhecimento internacional que se dedicou à formação de jovens e adultos, criando estratégias de alfabetização que promovessem uma educação integral e crítica.

Ferrari, Angotti e Tragtenberg (2009) explicam que Freire desenvolveu uma estratégia por investigação temática, voltada à alfabetização de adultos. 
Sendo assim, todo o processo de ensino era baseado em temas e deles eram retirados os conteúdos escolares necessários ao aprendizado do educando.

Inicialmente, a fim de que "o diálogo realmente se efetivasse, Paulo desenvolveu um trabalho em que o conhecido dos educandos se transformava em palavras geradoras, que possibilitavam a participação de todos" (BARRETO, 1998, p. 89). Tais palavras, retiradas do contexto em que se encontravam os educandos, seriam uma forma de se promover um ensino mais significativo aos alunos.

Barreto (1998) explica que o uso de palavras geradoras foi substituído, posteriormente, por Freire, para temas geradores. A ocorrência se deu pela compreensão do autor de que as palavras geradoras alcançavam, durante as discussões com os educandos, uma abrangência maior, pois elas eram, na verdade, assuntos que suscitavam discussão, investigação e geração de novos conhecimentos. Essa visão fica clara no seguinte discurso de Freire (1999, p. 102):

Não seria, porém, com essa educação desvinculada da vida, centrada na palavra, em que é altamente rica, mas na palavra'milagrosamente' esvaziada da realidade que deveria apresentar, pobre de atividades com que o educando ganhe a experiência do fazer, que desenvolveríamos no brasileiro a criticidade de sua consciência indispensável à nossa democratização.

Dessa forma, o ensino para esses alunos era baseado em temas de grande relevância para eles. Freire (2009) explica que, ao adotar esses temas, auxiliava os alunos não somente no processo de codificação/decodificação das letras; essa prática também despertava-os para a decodificação do meio, auxiliando as pessoas a realizarem uma releitura de situações antes olhadas de forma ingênua e acrítica.

Essa prática é possível, conforme explica o autor, a partir da adoção de situações que cercam a realidade de educandos e educadores. Esses temas precisam ser não só apreendidos, mas refletidos, a fim de que ocorra a tomada de consciência dos indivíduos sobre eles. Mais do que palavras, os temas são objetos de conhecimentos que deverão ser interpretados e representados pelos aprendizes. Ainda segundo Freire (2009), os temas geradores podem assumir caráter universal, ou temas mais peculiares, denominados também de situações-limites.

Um ensino, baseado na premissa dos temas geradores, perpassa as seguintes etapas, como explicadas por Freire (2009): a pesquisa dos temas é a etapa inicial, pois se configura no momento de leitura do mundo e dos assuntos que interferem diretamente na vida dos envolvidos; ao captar tais 
temáticas e apresentá-las aos educandos, ocorre o que Freire (2009) denomina de abstração, momento de se pensar sobre o tema, de dialogar sobre ele. Seria então a leitura codificada, ou seja, o que se conhece do tema e como ele é entendido na situação atual.

Posteriormente, faz-se uma análise mais crítica sobre o tema, na busca dos "porquês". Vai-se além dos limites aparentes das situações estudadas (situação-limite), partindo-se para a descodificação do tema, o que pode ser explicado como um processo de desconstrução do olhar ingênuo para a formação de uma visão mais crítica da realidade. Juntos, educando e educador buscarão desmistificar os pontos obscuros que serão clareados por meio do diálogo problematizador, tendo como pano de fundo a leitura e escrita, não de palavras soltas e sem sentido, mas de um universo de símbolos cheio de significados.

Gadotti (1991) faz uma apresentação didática das fases que o professor perpassará para desenvolver os conteúdos de ensino com a adoção de um tema gerador:

- investigação - momento em que o educador fará um levantamento de situações relevantes para os educandos a fim de se direcionar os temas de estudo; segundo Freire (2009), esse momento é muito importante, pois, na pesquisa do universo temático que envolve as relações homem-mundo, é preciso ter a consciência da necessidade de uma formação crítica que promova a releitura da situação em estudo. Nas palavras de Freire (2009, p. 56), "investigar o "tema gerador" é investigar, repitamos, o pensar dos homens referidos à realidade, é investigar seu atuar sobre a realidade, que é sua práxis"; - tematização - o tema é apresentado ao grupo ainda com a leitura realizada pelos educandos (codificada). Ao passo que se aprofunda o debate (descodificação) os alunos são levados a perceber que chegaram a um limite (situação-limite) e que há mais a se desvendar sobre o assunto;

- problematização - diálogo permanente entre a teoria e a prática, pois se reconhece que a primeira trará subsídios para uma melhor compreensão da realidade (práxis pedagógica).

Sendo assim, para ganhar um maior significado, o tema gerador precisa ser problematizado por meio de uma análise minuciosa dos envolvidos no processo educativo. Nessa perspectiva, Delizoicov, Angotti e Pernambuco (2002, p. 122) explanam que "a aprendizagem é resultado de ações de um 
sujeito, não é resultado de qualquer ação: ela se constrói em uma interação entre esse sujeito e o meio circundante, natural e social".

Portanto, é possível concluir que, com o ensino baseado na proposta de temas geradores, parte-se da contextualização, ou seja, de um assunto presente no dia a dia dos educandos e do educador. Ao buscar uma interpretação mais crítica da questão, percebe-se que os conhecimentos de senso comum não são suficientes para a plena compreensão do tema em pauta. Esse é o momento em que se provoca o aluno para a aprendizagem de forma mais significativa, pois consideram-se, diretamente, as necessidades de situações do seu cotidiano.

\section{Metodologia}

Com o objetivo de se promover uma educação que atendesse aos anseios dos educandos, esta pesquisa, de caráter exploratório, buscou investigar, através de um estudo de caso, como a proposta de ensino por meio de temas geradores poderia contribuir no processo de alfabetização de adultos, de forma a lhes oferecer uma visão mais crítica de seu contexto.

O campo de pesquisa foi um grupo composto por dez alunos do Programa Paraná Alfabetizado, no município de Ponta Grossa, Paraná Brasil. A pesquisadora era, na época, educadora do grupo, sendo que as aulas aconteciam quatro vezes por semana, em um salão paroquial cedido gentilmente pelo pároco local.

O grupo era formado, em sua maioria, por mulheres com idade entre trinta e setenta anos e, também com relação ao desenvolvimento da aprendizagem, marcado pela grande heterogeneidade.

Os temas geradores eram sempre retirados de assuntos do cotidiano dos educandos. Mas o enfoque deste trabalho está no desenvolvimento, após o terceiro mês de trabalho, quando se iniciaram as atividades com a temática "compras de mercado".

Considerando a proposta da teoria de Freire (2009), a investigação de um tema gerador perpassa o universo cultural na busca de situações cheias de significado. Considerando o grupo envolvido, as temáticas afloradas levavam muito em consideração a vida da dona de casa, seus anseios, angústias e realizações.

A opção por esse tema surgiu em uma conversa informal, entre a professora e as alunas, sobre estratégias para se gastar menos nas compras do início do mês. Uma educanda falou que seu esposo anotava o que ela precisava e ele ia ao mercado com a lista, já que ela nem fazia muita questão de ir, porque se dizia"muito atrapalhada" e o casal sempre acabava brigando. 
Percebe-se, então, que se poderia entrar em um novo tema gerador. A certeza se acentuou na fala de outra aluna, M. A.: "Como eu acho lindo as pessoas que vão com tudo anotadinho em lista [...]".

A questão de como administrar o tempo, o dinheiro e as necessidades da família é muito comum entre donas de casa. Fazer uma leitura mais crítica do ato de efetivar o fornecimento de alimentos durante o mês foi considerada uma opção de discussão, tendo em vista a questão de variação de preços e de estratégias adotadas pelos supermercados. Além disso, a riqueza das palavras que poderiam ser trabalhadas possibilitaria, em muito, contribuir para o aumento do vocabulário escrito dos alunos envolvidos, além de propiciar um trabalho com conteúdos de matemática de forma natural e significativa.

A avaliação do desenvolvimento da aprendizagem se deu de maneira formativa, utilizando-se como instrumento o portfólio, sendo arquivada uma atividade semanal para a construção do parecer descritivo do progresso de cada educando.

\section{A APLICAÇÃO DA ATIVIDADE E ANÁLISE DOS DADOS}

Para iniciar o trabalho com o tema gerador, foi realizada uma assembleia com os alunos e discutido como a temática proposta poderia contribuir para a formação dos envolvidos. Após isso, verificou-se na fala dos alunos que a maioria fazia suas compras em mercados da cidade por "costume", como apontaram alguns. A codificação do tema estava, então, sendo realizada conforme a proposta de Freire (2009), e aprofundar mais o assunto fez-se necessário; como situação-limite, percebeu-se que a grande dificuldade de leitura e interpretação de valores mostrou-se um fator dificultador aos alunos, iniciando-se, assim, o processo de descodificação do tema.

Ao iniciar as atividades, foi solicitado que os alunos guardassem todos os tabloides de supermercados onde eles compravam, para que se desenvolvesse um novo trabalho; na data marcada, todos, sem exceção, trouxeram o material solicitado. Essa prática possibilitou a construção de um novo saber de maneira aplicável e útil à vida cotidiana dos educandos.

Como primeira atividade, aos discentes foi proposto que fizessem uma lista de compras com itens que eles utilizavam em suas casas. Como estavam em diferentes fases da escrita, houve listas escritas de diferentes maneiras: marcadas pelo nível pré-silábico, outras pelo silábico, silábicoalfabético e alfabético.

Depois da leitura das listas individuais, organizou-se uma única lista para o desenvolvimento dos trabalhos subsequentes, na qual foram incluídos os itens que mais apareceram nas anotações dos discentes. A turma 
decidiu que deveriam ser elencados quinze itens, e esses foram escritos pela professora no quadro-negro. A lista final do grupo ficou assim: arroz, feijão, macarrão, massa de tomate, margarina, bolacha, sabão em pedra, sabão em pó, água sanitária, sabonete, fubá, achocolatado, alho, leite e papel higiênico. Essas, então, foram as palavras geradoras, elencadas para o processo de alfabetização.

Posteriormente, foi desenvolvida a segunda atividade: comparar, nos tabloides, os preços dos produtos da lista de compras do grupo. Os educandos escolheram para essa atividade três dos supermercados da cidade que eles mais frequentavam.

Antes de dar prosseguimento à atividade, foram recapitulados os algarismos e sua relação com quantidade e, a seguir, com o dinheiro, sendo usado como recurso o "dinheirinho" (impresso representando as notas de real). A grande maioria não sentiu dificuldade em trabalhar com números, porém, muitos demonstravam ainda dificuldade com valores, conteúdo que foi trabalhado pela educadora durante as aulas seguintes.

Em outro encontro, foi solicitado aos educandos que refizessem a lista em uma folha de sulfite; os próprios alunos iam recordando os itens que tinham estipulado anteriormente e anotando na folha. Percebeu-se que muitos, apesar de anteriormente já terem desenvolvido atividades com aquelas palavras, não recordavam mais como eram escritas. Então, foi sugerido que recortassem imagens dos itens presentes nos tabloides e colassem ao lado da palavra. Uma das alunas, ao ver no tabloide o nome do produto, imediatamente apagou a anotação de seu caderno e copiou atenciosamente como a palavra era grafada: arroz (ela havia escrito arois).

A terceira etapa desse trabalho foi a tomada de preços. Para tanto, solicitou-se aos educandos que recortassem o nome de cada mercado, e montassem uma tabela na mesma folha de papel sulfite, elencando os produtos e anotando os preços de cada item apresentados nos três mercados.

Essa etapa possibilitou que a professora trabalhasse os algarismos, os números decimais e o sistema monetário, ao mesmo tempo explicando o uso desses conteúdos da matemática na vida cotidiana. Ao final, pôde-se visualizar melhor os produtos e qual o seu valor em cada um dos estabelecimentos escolhidos, por meio da comparação de preços. Houve aqui as primeiras leituras críticas da realidade que nos cerca: os próprios alunos perceberam que os mercados não fazem as mesmas ofertas. Cada um oferece preços mais baixos em alguns itens e mais altos em outros. Algumas falas dos educandos podem ilustrar essa visão:

- Nossa, parece que eles até se combinam - disse a aluna M. A. 
- O ideal é comprar somente as ofertas porque aí, sim, a gente vê alguma economia - complementou C. K.

Pode-se verificar nos diálogos do grupo a proposta de Freire (1981), embasada na partida do conhecimento ingênuo para o conhecimento crítico. Os preços nos maiores supermercados da cidade não eram analisados pelos alunos (e muitas vezes, nem pela professora). A partir de então, todos puderam refletir de maneira mais criteriosa na hora das compras.

Esse trabalho durou dois meses, e nele vários conhecimentos foram explorados: a escrita das palavras presentes na lista de compras, suas famílias silábicas e várias outras palavras que delas surgiram; os números, o sistema monetário, o sistema decimal (com os centavos); escrita de nomes próprios (nome dos mercados e também das marcas dos produtos); operações básicas (para somar o valor total da lista). Assim pôde-se trabalhar de forma contextualizada e, com isso, tornar o aprendizado mais interessante ao aluno.

Além disso, essa prática propiciou refletir sobre a importância da concepção de ensino que o professor possui e como, a partir dela, os procedimentos de ensino serão direcionados.

A reflexão de Paulo Freire nos demonstra qual deveria ser a concepção de ensino dos professores:

Por isso também é que ensinar não pode ser um puro processo, como tanto tenho dito, de transferência de conhecimento do ensinante ao aprendiz. Transferência mecânica de que resulte a memorização maquinal que já critiquei. Ao estudo crítico corresponde um ensino igualmente crítico que demanda necessariamente uma forma crítica de compreender e de realizar a leitura da palavra e a leitura do mundo, leitura do contexto. (FREIRE, 2001, p. 264)

Dar significado ao que se está ensinando e promover uma leitura crítica da realidade que nos cerca deveriam ser atitudes presentes nas práticas educativas, não só em EJA, mas em todas as modalidades de educação.

Outro ponto percebido durante o processo de desenvolvimento desse último tema gerador foi a diminuição no número de faltas dos alunos nas aulas. Como a atividade estava interessante, houve uma participação significativa durante as aulas e também nas atividades de casa.

O trabalho de maneira interdisciplinar, como o aqui relatado, possibilita o rompimento com a "compartimentalização" dos conteúdos: momentos das aulas somente de matemática e outras somente de português. Além disso, o que se verifica com essa experiência é que se pode trazer a 
contextualidade aos conteúdos estudados; isso possibilitou a concretização do aprendizado, uma vez que esse foi vivido e experimentado.

Nos momentos em que as atividades aconteciam, foi possível observar que a falta de conhecimento de escrita e de conceitos básicos da matemática estava sendo superada aos poucos; e o envolvimento com aquele trabalho foi tão intenso que todos se sentiam aptos a fazer o que era proposto. O repertório de palavras geradoras havia aumentado consideravelmente e, por isso, muitos já se arriscavam a escrever pequenos textos, devido à relação que faziam entre as famílias silábicas que aprenderam. Outro ponto a ser considerado é sobre os conceitos matemáticos trabalhados; ficou aparente que eles inicialmente reconheciam números, mas não os valores, conteúdos escolares que faziam também parte de seu cotidiano. Posteriormente, o conhecimento desenvolvido oportunizou a compreensão e a visualização mais crítica sobre esses mesmos valores, possibilitando-lhes manusear melhor seu dinheiro ao desenvolverem habilidades com soma e subtração.

Como mudança na vida dos alunos, o que se pode indicar foi uma conquista de dignidade, uma vez que poderiam, por meio da leitura, identificar o nome dos produtos, as ofertas apresentadas e identificar os preços, conferindo-lhes valores. A autonomia conquistada por meio da leitura, da escrita e do diálogo problematizador ratifica o que Freire defendeu durante toda sua vida: o direito à cidadania.

\section{CONCLUSÃo}

Ensinar jovens e adultos a ler e a escrever não foi um problema discutido apenas na atualidade, pois desde a década de 1940 houve investidas públicas, objetivando diminuir os números do analfabetismo. Contudo, o diferencial foi a concepção de formação para essa faixa da população, sendo que o maior marco foi, sem dúvida, o enfoque dado por Paulo Freire. Ele mostrou que, por trás de todo ato educacional, há sempre um ato político e, por isso, conclui-se que de maneira alguma a educação é neutra. Assim como ela foi (e ainda é) utilizada para dar continuidade à sociedade, também poderá ser um forte instrumento de transformação social.

O trabalho com disciplinas isoladas faz com que se dificulte que a educação cumpra seu papel: o de formar o cidadão. É preciso que haja a vinculação entre o conhecimento científico e os acontecimentos e vivências dos alunos. Aliando isso à necessidade de construção de reflexões mais críticas acerca da realidade que nos envolve, percebe-se que o trabalho com educação vai muito além do que transferir informações: baseia-se em construir conhecimento. 
Portanto, quando Freire sugere o trabalho com temas geradores, não é por acaso. Essa proposta vem ao encontro das necessidades da população, outrora excluída politicamente (e até mesmo socialmente), por proporcionar a aquisição do conhecimento da leitura e da escrita e sua relação com suas vidas.

Essas premissas puderam ser observadas no grupo pesquisado, uma vez que o tema proporcionou não só a aprendizagem da língua escrita e da matemática, mas também uma releitura das situações cotidianas.

Sendo assim, foi possível concluir que a proposta de Paulo Freire contempla uma educação formadora de cidadãos mais críticos, pois thes abre a possibilidade de ler não apenas o que está evidente, mas também as entrelinhas.

\section{USE OF GENERATOR THEMES IN THE PROCESS OF ADULT LITERACY}

ABSTRACT: This article set out to describe the process of research undertaken with students in an adult literacy program, through a case study. The research involved activities using the Paulo Freire methodology of using generator themes. It was seen that teaching through themes related to everyday life directly influences students' involvement in the classroom, and consequently, a successful learning outcome. It was found that this proposal meets the needs of learners, in the sense that it leads to knowing how to read and write and provides them with knowledge relevant to their lives.

KEY WORDS: Adult literacy. Generator themes. Paulo Freire.

\section{REFERÊNCIAS}

BARRETO, V. Paulo Freire para educadores. São Paulo: Arte \& Ciência, 1998.

BRASIL. Lei de Diretrizes e Bases da Educação Nacional n. 9394/96. Brasília, 1996.

DELIZOICOV, D.; ANGOTTI, J. A. P.; PERNAMBUCO, M. M. Ensino de ciências: fundamentos e métodos. São Paulo: Cortez, 2002. (Docência em Formação).

DI PIERRO, M. C.. Notas sobre a redefinição da identidade e das políticas públicas de educação de jovens e adultos no Brasil. Educação e Sociedade, Campinas, v. 26, n. 92, p. 1115-1139, 2005.

FERRARI, P. C.; ANGOTTI, J. A. P.; TRAGTENBERG, M. H. R.. Educação problematizadora à distância para a inserção de temas contemporâneos na formação docente: uma introdução à teoria do caos. Ciência e Educação, v. 15, n. 1, p. 85-104, 2009. Disponível em: $<$ http://www.scielo.br/scielo.php?pid=S1516-73132009000100005\&script=sci_arttext>. Acesso em: 25 ago. 2010. 
FREIRE, P. Carta de Paulo Freire aos professores. Estudos avançados, São Paulo, v. 15, n. 42 , p. 259-268, 2001.

FREIRE, P. Educação como prática da liberdade. Rio de Janeiro: Paz e Terra, 1999.

FREIRE, P. Pedagogia do oprimido. 48. reimp. São Paulo: Paz e Terra, 2009.

GADOTTI, M. Convite à leitura de Paulo Freire. 2. ed. São Paulo: Scipione, 1991.

OLIVEIRA, I. B; PAIVA, J. Educação de jovens e adultos. Rio de Janeiro: DP\&A, 2004.

PILETTI, C. Filosofia da educação. São Paulo: Ática, 1997.

JAQUELINE DE MORAIS COSTA é graduada em Pedagogia pela UEPG e mestre em Ensino de Ciência e Tecnologia pela UTFPR. Atua como professora de ensino superior pela SECAL - Faculdades Santa Amélia - e como Supervisora Pedagógica pelo CESCAGE - Centro de Ensino Superior dos Campos Gerais.

E-mail: jaque_morais@pop.com.br 